\title{
A cultura como conceito operativo: Antropologia, Gestão Cultural e algumas implicações políticas desta última
}

\author{
La cultura como concepto operativo: Antropología, gestión cultural y \\ algunas implicaciones políticas de este último
}

\section{The culture as operative concept: Anthropology, Cultural Management and some implications politics of this last one}

\author{
Caio Gonçalves Dias*
}

Palavras chave:

Teoria Cultural

Antropologia

Gestão Cultural

Significados socialmente compartilhados

\section{Palabras clave:}

Teoría cultural

Antropología

Gerencia cultural

Significados compartidos social
Resumo:

O presente artigo tem por objetivo analisar a dimensão operativa - como possibilitador de uma prática antropológica central, a etnografia - do conceito de cultura. Para isso, parte da análise de três autores contemporâneos, Geertz, Sahlins e Barth. A partir dessa elaboração, procura discutir a definição de gestão cultural, dando ênfase para algumas das implicações políticas de suas práticas.

\author{
Key words: \\ Cultural theory \\ Anthropology \\ Cultural Management \\ Meanings socially shared
}

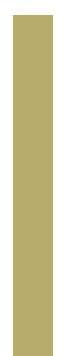

Resumen:

El actual artículo tiene para que el objetivo analice la dimensión operativa del concepto de la cultura - como possibilitador de una práctica etnografica. Para este, la parte del análisis de tres autores contemporáneos, Geertz, Sahlins y Barth. De esta elaboración, busca para discutir la definición de la gestión cultural, dando al énfasis para algo de las implicaciones políticas de su prácticas.

\section{Abstract:}

The present article intents to analyze the operative dimension of the culture concept. For this, presents the analysis of three contemporaries authors, Geert, Sahlins and Barth. From this elaboration, it looks for to argue the definition of cultural management, giving to emphasis for some of the practical implications on its politics.

\footnotetext{
* Bacharel em Produção Cultural pela Universidade Federal Fluminense.

Mestre e Doutorando em Antropologia Social pelo Museu Nacional da Universidade Federal do Rio de Janeiro.
} 


\section{A cultura como conceito operativo: Antropologia, Gestão Cultural e algumas implicações políticas desta última}

Já há algumas décadas, os debates em torno de definições sobre cultura deixaram de ser feitos majoritariamente no âmbito das discussões antropológicas. Se mesmo antes da antropologia afirmar-se enquanto disciplina a partir da segunda metade do século XIX havia discussões importantes nesse sentido, o que se observou posteriormente foi uma centralização, nessa disciplina, das discussões que se preocupavam com definições do termo. Certamente havia debates importantes em outras áreas; mas elas tiveram impacto menor tanto para a teoria antropológica, como para o entendimento do mundo social em outros contextos. Foi só a partir da década de 1960, que outras elaborações sobre cultura tiveram implicações para própria antropologia, especialmente com os estudos culturais ingleses e com o orientalismo saidiano.

Foi também a partir desse momento - com movimentos anteriores, certamente - que a própria noção de cultura expandiu-se de modo a ser operada por outros agentes em suas práticas de trabaIho. Nesse contexto, a qualificação "cultural" passou a ser utilizada de muitas maneiras, com objetivos distintos, tanto no mundo acadêmico como entre gestores públicos e cada vez mais em outras esferas do cotidiano.

Seria possível pensar essas articulações a partir do surgimento de novos agentes socialmente reconhecidos. Se é possível, por exemplo, explicar que a ascensão da juventude como força social na década de 1960 fez com que as práticas políticas fossem orientadas nesse sentido, talvez seja igualmente importante pensar como tecnologias de governos fazem com que certas coletividades surjam como agentes sociais significativos. Dito de outro modo, não há como dissociar esse surgimento como coletividade representativa das próprias ações de governamentalidade - em sentido foucaultiano (2008, especialmente aula de 1 de fevereiro) - que as reconhecem e atuam para e a partir delas.

A própria emersão do cultural como qualificador se liga a uma série de tecnologias de governo que atuaram de modo sistêmico também nesse contexto. Não por acaso essa ascensão do cultural - ou a virada cultural, como propõe Jameson (2006) e uma série de outros autores - pode ser compreendida como um movimento onde operaram agenciamentos diversos em distintos âmbitos: na academia, na produção intelectual, na administração pública, nas ações de agências internacionais, etc.

As elaborações discursivas que acompanham esses agenciamentos reportam-se a inúmeros conceitos de cultura, parte significativa importada da antropologia de modo mais ou menos frouxo. Uma questão que parece ter sido deixada de lado nesses processos é uma característica fundamental de boa parte dos conceitos antropológicos de cultura: eles são operativos. Isso significa que, mais do que uma abstração conceitual, a cultura serviu para justificar e embasar um método central para antropologia: a etnografia. Reconhecer essa ponderação é central, pois - e não se está tratando aqui de se está falando de características que seriam basilares para construção de - e reflexão sobre - práticas e não apenas para justificativas de ações em curso.

São muitos os processos, tanto elaborados por sujeitos individuais como 
por agentes institucionais da administração pública e do setor privado, que, se estão acompanhados do "cultural" como adjetivador, não parecem preocupados com as implicações do uso do termo a partir de uma definição do que seria cultura.

A gestão cultural, como saber e prática, pode ser pensada devedora desse contexto. A indústria cultural e do entretenimento já podem ser encontradas amadurecidas na primeira metade do século $X X$; mas um profissional que se reconheça como "gestor cultural" é um fenômeno relativamente recente, que data mais ou menos da década de 1980 (Bonet et al., 2006).

É com esse quadro que este texto dialoga. Seu objetivo central, nesse sentido, é expor três autores centrais para Antropologia contemporânea - Geertz, Sahlins e Barth -, dando ênfase para a maneira como seus conceitos de "cultura" foram elaborados para dar conta de suas práticas de compreensão do mundo social, notadamente através do trabalho etnográfico. Em outro momento, será conceituada a gestão cultural a partir dessas reflexões, explorando algumas implicações políticas de sua prática a partir dessa reconceptualização.

Geertz, Barth e Sahlins são da mesma geração; nasceram, respectivamente, em 1926, 1928 e 1930. Participaram de momentos cruciais para formação da Antropologia contemporânea e representam, contudo, tradições intelectuais bastante distintas. Geertz, graduado em Filosofia, doutorou-se em Harvard no pioneiro departamento de relações sociais criado por Parsons; Barth, por sua vez, graduou-se em Ciências Sociais na Universidade de Chicago, em um momento extremamente importante da Escola, e foi orientado por Edmund Leach em seu doutorado em Cambridge; Sahlins, de seu lado, fez a graduação em Psicologia na Universidade de Michigan e o doutorado na Universidade de Colúmbia, sob orientação de Julian Steward.

Em comum, tem o fato de terem passado por mudanças intelectuais ao longo de suas carreiras. A mais drástica é a de Sahlins, que abandona um paradigma neo-evolucionista a favor de um culturalismo estruturalista. Geertz troca as discussões sobre sociedades camponesas por uma antropologia interpretativa não mais diretamente relacionada a esse tipo de debate. E Barth, num movimento de continuidade, passa a preocupar-se mais com a questão dos significados e identidades, ao passo que anteriormente dedicava-se ao estudo de sistemas políticos - tema no qual esse tipo de discussão não era tão central, apesar de presente. $O$ texto que se segue se organiza a partir de metáforas explicativas da cultura utilizadas pelos autores: teia, em Geertz; corrente, em Barth; e estrutura, em Sahlins.

TEIA

Em "Uma descrição densa", Clifford Geertz define seu projeto para Antropologia: uma nova abordagem em que o fazer antropológico tomaria um viés interpretativo. O autor utiliza um conceito semiótico de cultura, assumindo uma inspiração weberiana. Em suas palavras: "o homem é um animal amarrado a teias de significados que ele mesmo teceu, assumo a cultura como sendo essas teias e sua análise; portanto não como uma ciência experimental em busca de leis, mas como uma ciência interpretativa à procura de significados" (GEERTZ, 1978 A, p. 15).

O autor pressupõe que a definição de uma ciência seria possibilitada através do que fazem os seus praticantes; no caso da Antropologia, etnografia - que o 
autor supõe ser método exclusivo da disciplina. A partir de um exercício de identificação de afazeres no processo de construção da etnografia, Geertz postula que o esforço intelectual representado no trabalho deste tipo seria marcado por uma descrição densa, que fosse capaz de entender como os diversos significados são hierarquizados nas diferentes situações; deste modo, o esforço da descrição densa seria possibilitar

uma hierarquia estratificada de estruturas significantes em termos das quais os tiques nervosos, as piscadelas, as falsas piscadelas, as imitações são produzidos percebidos e interpretados, e sem os quais eles de fato não existiriam (nem mesmo as formas zero de tiques nervosos as quais, como categoria cultural, são tanto não-piscadelas como as piscadelas são não-tiques), não importa o que alguém fizesse ou não com sua própria pálpebra (Op. Cit., p.17).

Os dados etnográficos, nesse contexto, seriam escolhas feitas pelo antropólogo entre as construções simbólicas empregadas pelos nativos. Nesse sentido, não haveria como chegar a uma realidade propriamente, mesmo nos dados - em tese - livres de explicações ou interpretações. Esse tipo de dados possivelmente não existe; o antropólogo estaria criando uma explicação - em todos os momentos da pesquisa, mesmo os mais iniciais, é preciso ressaltar - em torno de explicações. Assim, a Antropologia de Geertz seria caracterizada pelo esforço interpretativo e seu resultado deveria ser entendido como uma ficção - no sentido de que é uma construção e, portanto, não corresponde, e nem poderia, à realidade de fato.

O trabalho do Antropólogo, deste modo, estaria centrado na identificação das estruturas de significação mais expressivas empregadas pelos sujeitos estudados, determinando sua base social e formatando sua hierarquia. Deste modo, o trabalho antropológico, segundo Geertz, poderia ser aproximado ao do crítico literário, que também hierarquiza estruturas de significados, atribuindo-lhes maior ou menor importância. Neste contexto, o que o etnógrafo enfrenta é uma "multiplicidade de estruturas conceptuais complexas, muitas delas sobrepostas ou amarradas, irregulares ou inexplícitas, e que ele tem que, de alguma forma, primeiro apreender depois apresentar" (GEERTZ, 1978 A, p. 20). A maneira, entretanto, como essa hierarquização deveria ser executada não é explicitada pelo autor.

A análise antropológica deve, para Geertz, ser feita em dimensão microscópica. "O antropólogo aborda caracteristicamente tais interpretações mais amplas e análises mais abstratas a partir de um conhecimento muito extensivo de assuntos extremamente pequenos" (Op. Cit., p. 31). Deste modo, para além da representatividade de uma realidade mais ampla, ou de uma experiência laboratorial, o trabalho antropológico deveria ser definido pelo fato de estudar questões sociológicas importantes também para outras disciplinas, mas em espaços ou grupos sociais menores.

\section{Nesse sentido,}

o locus do estudo não é o objeto de estudo. Os antropólogos não estudam as aldeias (tribos, cidades, vizinhanças...), eles estudam nas aldeias. Você pode estudar diferentes coisas em diferentes locais, e algumas coisas - por exemplo, o que a dominação colonial faz às estruturas estabelecidas de expectativa moral - podem ser melhor estudadas em localidades isoladas. Isso não faz do lugar o que você está estudando (Op. Cit., p. 32). 
Assim, dá-se ênfase para o que se estuda. $\mathrm{O}$ valor das descrições etnográficas

está no fato de fornecerem à mente sociológica material suficiente para alimentar. (...) Os megaconceitos com os quais se aflige a ciência social contemporânea - legitimidade, modernização, integração, conflito, carisma, estrutura... significado podem adquirir toda a espécie de atualidade sensível que possibilita pensar não apenas realista e concretamente sobre eles, mas, o que é mais importante criativa e imaginativamente com eles (Op. Cit., pp. 34-35).

A construção teórico-metodológica que Geertz propõe tem, portanto, pontos bem definidos. O modo como o autor a emprega, contudo, merece considerações.

O trabalho sobre rinhas de galos em Bali (GEERTZ, 1978 B) pode ser pensado nesse sentido. A construção do texto é bastante significativa - e dizer que essa construção é ocasional seria o mesmo que negar a inteligência de Geertz -, já que acaba por direcionar a leitura de modo que a exposição dos "fatos" seja convenientemente descolada da análise - que é também uma proposição teórica. Geertz começa com uma simpática historieta de campo, onde por um incidente com a polícia local, o autor acaba por se esconder com nativos e é através desta experiência que seu trabaIho de campo começa efetivamente. Passa então a uma exposição mais dura - e, como sempre, muito bem escrita - do funcionamento das rinhas de galo; e termina com uma analogia pouco convincente das ideais expostas até então com a análise de textos. Não fica claro, portanto, o porquê do entendimento das rinhas de galo enquanto texto: a proposição teórica parece não suportar o embasamento etnográfico - ou o contrário.
O balinês de que trata o texto é uma espécie de ente coletivo genérico. Geertz supõe que todos os balineses compartilham dos mesmos significados; e não dá espaço para que a briga de galos seja experimentada de formas diferentes por diferentes pessoas. Uma faceta cultural de algum modo tomada como representativa de outros; uma polifonia transformada em uníssono; a briga de galos como representativa do balinês. A análise de Geertz faz a vida do balinês parecer centrada nas brigas de galos. Sem negar a importância que essa prática possa ter, sua inserção no contexto cotidiano mais amplo não é explorada pelo autor, resultando numa interpretação hermética.

Seu trabalho sobre senso comum (GEERTZ, 2000), por outro lado, evidencia o modo como o autor compreende o mundo social; no texto fica claro um descolamento entre sociedade e cultura, entendidas como sistemas distintos. A influência de Parsons é importante nessa situação. "The Social System", obra do sociólogo publicada pela primeira vez em 1951, trabalha exatamente por uma visão do mundo social em três domínios distintos: o social, o da personalidade e o cultural (ver PARSONS, 1979). A essa divisão correspondia uma divisão do trabalho entre sociólogos, psicólogos e antropólogos. Exatamente durante a década de 1950, Geertz realizava seu doutorado no departamento de relações sociais da Universidade de Harvard (ver HANDLER \& GEERTZ, 1991), criado por Parsons. Essa segmentação do mundo social acompanhou todo essa construção mais ampliada do pensamento de Geertz.

Nesse contexto, para além de definições mínimas essencialistas - como na busca por formas elementares de características que nos são próprias - deve-se entender as maneiras singulares que cada cultura possui em seus processos de 
sistema; precisam-se verificar, assim, as estratégias de sistematização dentro da sociedade em si mesma.

É com essa perspectiva que Geertz pretende analisar o senso comum, ou seja, como sistema cultural deliberadamente estabelecido; ou ainda, como um corpo organizado de pensamento deliberado. O que contraria a idéia central surgida do pensamento advindo do senso comum, que se pretende como opinião resgatada diretamente da experiência e não de reflexões deliberadamente elaboradas acerca destas experiências. Opera-se, assim, "uma distinção entre uma mera apreensão da realidade feita casualmente e uma sabedoria coloquial, com pés no chão, que julga ou avalia esta realidade" (GEERTZ, 2000, p. 115).

O bom senso, com isso, precisa ser visto - do mesmo modo que todo sistema cultural - como construção e sujeito a padrões de juízo definidos.

Em suma, é um sistema cultural, embora nem sempre muito integrado, que se baseia nos mesmos argumentos que se baseiam outros sistemas culturais semelhantes: aqueles que os possuem têm total convicção de seu valor e de sua validade. Neste caso, como em tantos outros, as coisas têm o significado que lhes queremos dar (Op. Cit., p. 116).

Uma definição básica do senso comum seria aquilo que o "homem comum pensa quando livre das sofisticações vaidosas dos estudiosos" (Idem). O bom senso, nesse contexto, teria uma capacidade categorizante e, como tal, em alguma medida estigmatizadora. "O bom senso não é aquilo que uma mente livre de artificialismo apreende espontaneamente; é aquilo que uma mente repleta de pressuposições conclui" (Ibidem, p. 127).
Uma análise transcultural do senso comum só seria possível em termos estilísticos. Existiria, assim, para além do que diz respeito ao conteúdo, características do bom senso observáveis nas diversas culturas; seriam a naturalidade, praticabilidade, leveza, não-metodicidade e acessibilidade. Não se trataria, portanto, de uma sistematização do conteúdo, tarefa impossível por definição, mas "evocar o som e vários sinais que são geralmente reconhecidos como pertencendo ao senso comum" (Ibidem, p. 141).

Essas questões geertzianas aqui apresentadas - cultura como uma teia de significados, apreensão de práticas culturais como textualidades e análise sociológica a partir de sistemas - são centrais para visão da cultura como operadora de práticas. De um lado, temos a definição de um universo simbólico que circunscreve as preocupações antropológicas; de outro se tem um método para dialogar com esse universo e interpretá-lo, a textualização; e por fim, a divisão do mundo social em sistemas é operadora de um cercamento de domínios, que, se pensa a cultura em relação ao social e individual, reserva para o trabalho antropológico a atuação central a partir de apenas um desses domínios.

\section{CORRENTE}

Em entrevista concedida a Robert Anderson, Fredrik Barth fez a seguinte afirmação:

Look at this landscape [vista da janela de sua casa em Oslo], I mean, all the trees that fortuitously... the seeds have dropped there, then they aggregate together and create a situation, that yes, you can characterize it by abstract structural things, but it hasn't been generated by those abstractions. 
It has been generated by elemental processes where each event is pretty fortuitous. That fascinates me; I think its much more fun than to abstract until you have something that is intellectually clean and exaggerated. And much less able therefore to handle time and change (ANDERSON; BARTH, p. x-xi).

A visão que Barth possui do mundo social caminha nessa direção. Para além das formulações que buscassem seu enquadramento, de modo a desvendar apenas uma série de regularidades, a dimensão que interessa ao autor é a que leva em conta o caráter fortuito da vida cotidiana. Ao invés de excluir o que pudesse comprometer uma harmonia analítica, Barth interessa-se pelos processos; pela interação entre as questões mais rasteiras do dia-a-dia e o constrangimento de certas instituições sociais:

Methodologically, I believe the key element to be the focus on efficient causes: the cultural and interaction enablements and constraints that affect actors, with consequences that can be seen in the patterning of resulting acts and their aggregate entailments. In this way, the micro-level where most of our anthropological observations are located and the macro-level of institutional forms and historical processes, can be integrated. (BARTH, 1990, p. 651).

A análise cultural, nesse contexto, deveria levar em conta a matriz mais ampla de processos com a qual se liga; as questões culturais não podem ser entendidas como sendo destacados da dimensão material e das realidades objetivas, do mesmo modo como essas últimas dimensões isoladamente não podem ser entendidas como explicativas. Barth, seguindo o que chama de uma confluência entre correntes intelectuais divergen- tes, acredita que as realidades das pessoas são culturalmente construídas. $\mathrm{O}$ autor, entretanto, vai além ao pontuar que os padrões culturais são resultados de processos culturais específicos, e que como tal podem ser identificados.

As abordagens estruturalistas e interpretativistas, das quais Barth discorda, "servem como meio para que seus atores consigam evitar todos os aspectos problemáticos do mundo que nos cerca; reafirmam silenciosamente o pressuposto de que a cultura apresenta uma coerência lógica generalizada, sem explorar a extensão e a natureza dessa coerência" (BARTH, 2000, p. 110).

Não se trata, entretanto, de afirmar que não haja padrão nos comportamentos humanos. A proposta do autor é a busca por diversos padrões parciais e aparentemente conflitantes que colaboram na conformação de certo quadro sociológico. A coerência, nesse sentido, deve sempre ser alvo de desconfiança.

Nesse contexto, é necessário que se compreenda o trânsito dos indivíduos entre os diversos universos discursivos, que se interpenetram, sobrepõem, excluem. Deste modo, a construção cultural da realidade não vem de uma fonte única; ao contrário, precisa-se pensar na interação de diversas tradições culturais - de origens diversificadas e nem sempre determináveis - que colaboram na formatação dessa realidade. Uma visão plural pode ser possibilitada a partir da análise através de "correntes de tradição cultural"1,

cada uma delas exibindo uma agregação empírica de certos elementos e formando conjuntos de características coexistentes que tendem a persistir ao longo do tempo, ainda que nas vidas das populações locais e regionais 
várias dessas correntes possam misturar-se (Op. Cit., p. 123).

Barth entende que para identificação desse tipo de corrente, que representariam a coerência na cultura, é necessário que o pesquisador se volte para as questões empíricas e, conseqüentemente para os processos sociais. Deste modo, o trabalho analítico não é produtivo quando se perde em abstrações formais; em primeiro plano deve-se procurar o modo de operar de cada um desses componentes culturais, empregando "metaphors of process, focused activity, marginal change, cumulative transformation, and above all think more imaginatively in terms of determined models of formative, generative processes (BARTH, 1990, p. 652)".

Essa proposta parece ainda mais interessante, segundo o autor, quando o antropólogo estuda sociedades diferentes da sua. Essa perspectiva foi, por exemplo, importante para o trabalho de Barth em Bali, pois "o conjunto das imagens luxuriantes do bali-hinduísmo parece basear-se em premissas e epistemologias diferentes das nossas, e conseqüentemente é difícil rastrear e compreender sua existência se ela for abstraída de um contexto de práxis social" (BARTH, 2000, p. 125).

O conceito de cultura com o qual trabalha Barth é, deste modo, também de natureza semiótica, ao passo que as correntes de tradição cultural são entendidas como universos discursivos que compartiIham certos significados. A ênfase, entretanto, é para os significados em uso, de modo que o entendimento de como operam é fundamental para uma reconceptualização da cultura. "Desse modo, devemos ser capazes de identificar as partes envolvidas nos discursos que se dão, e 'o segmento do processo do mundo infinito e sem sentido sobre os quais elas conferem significado e sentido"' (Op. Cit., pp. 127-128).
O lugar do significado na teoria cultural de Barth, nesse contexto, é fundamental e o autor faz observações importantes com relação a sua compreensão. A primeira delas é a de que o "significado é uma relação"; assim, para além de algo cristalizado enquanto expressão cultural, trata-se de uma relação entre observador e o signo. O significado, desta maneira, deve ser visto como algo atribuído, de modo que só pode ser entendido na relação do ator e de um fragmento de cultura com as experiências e conhecimentos desse ator específico.

Outro ponto explorado por Barth é o fato da "cultura ser distributiva", ou seja, seu compartilhamento não é absoluto. Atores diferentes têm acessos diferentes às estruturas significativas; algumas vezes, "as estruturas mais significativas da cultura - ou seja, aquelas que mais conseqüências sistemáticas têm para os atos e relações das pessoas - talvez não estejam em suas formas, mas sim em sua distribuição e padrões de não-compartilhamento" (BARTH, 2000, p. 128).

No mesmo sentido, os atores devem ser pensados como estando sempre posicionados. Deste modo, para além da relação entre vivência individual, cultura e contexto, deve-se atentar para o modo como os significados operam e diferenciam relações entre os atores. Barth recomenda que, para além do diálogo com os nativos, os antropólogos dêem importância para os diálogos entre os próprios nativos. Seria revelado, assim, que os diferentes atores compreendem o mesmo evento de maneiras distintas, de acordo com a posição que ocupam em determinada situação sociológica.

Barth ressalta, por fim, que os eventos não podem ser entendidos em termos de intenções individuais de atores individuais; ao contrário, eles 
seriam resultado do jogo entre causalidade e interação social. Trata-se, portanto, da faceta fortuita da ação social, que ressalta seu caráter dinâmico, que opera por meios processuais. "Precisamos incorporar ao nosso modelo de produção da cultura uma visão dinâmica da experiência como resultado da interpretação de eventos por indivíduos, bem como uma visão dinâmica da criatividade como resultado da luta dos atores para vencer a resistência do mundo" (BARTH, 2000, p. 129).

É importante termos, em mente, a partir de Barth, o caráter dinâmico da cultura, de maneira que suas interlocuções consigam se estabelecer em termos processuais. Por outro lado, é central reconhecer algumas das dimensões dos significados compartilhados que compõem a cultura: eles são distributivos, de modo que nem todos os agentes de determinada situação social elaboram interpretações coincidentes; no mesmo sentido, é importante ter em mente de que um indivíduo se relaciona com certa porção de cultura a partir de categorias anteriormente estabelecidas; e, por fim, os significados precisam ser pensados como relações entre observador e signo.

\section{ESTRUTURA}

Em "Cultura e Razão Prática", Sahlins explora a noção de que para além de uma razão prática - uma visão utilitária da ordem social que teria na maximização de relações meios-fins com intuito de manutenção da população humana ou da ordem social seu pilar explicativo -, existe uma razão de natureza simbólica ou significativa. Toma, deste modo,

como qualidade distintiva do homem não o fato de que ele deve viver num mundo material, circunstância que compartilha com todos os organismos, mas pelo fato de fazê-lo de acordo com um esquema significativo criado por si próprio, qualidade pela qual a humanidade é única. Por conseguinte, toma-se por qualidade decisiva da cultura (...) não o fato de essa cultura poder conformar-se a pressões materiais, mas o fato de fazê-lo de acordo com um esquema simbólico definido, que nunca é o único possível. Por isso, é a cultura que constitui utilidade (SAHLINS, 2003, pp. 7-8).

O trabalho de Sahlins tem por questão central o fato de estruturas simbólicas estarem presentes nas utilidades materiais. Bastante erudita, a obra é um diálogo, principalmente, com o marxismo e o estruturalismo, afirmando os caracteres localizados culturalmente do último e historicamente do primeiro. Se o projeto de Sahlins soa pretensioso - já que acaba por formular uma espécie de meta-teoria que pudesse de algum modo abarcar e localizar os ímpetos das duas correntes teóricas citadas -, a maneira como o autor conduz o texto e a solidez da bibliografia que utiliza servem para contrabalançar a sensação. A empreitada intelectual a que se propõe é, portanto, admirável e justifica-se no sucesso obtido pelo trabalho - amplamente citado, debatido e editado. Há que se criticar, entretanto, o modo pouco cuidadoso como o autor faz generalizações e como compara situações etnográficas bastante distintas.

O foco da teoria de Sahlins é o debate entre o prático e o significativo, que seria determinante para as ciências humanas de modo geral. Aos debates acerca das diversas relações entre o objetivo e o subjetivo, a Antropologia, de seu lado, proporia algo diferente: "um terceiro termo, a cultura, não simplesmente mediando a relação humana com o mundo através de uma lógica social de significados, mas compreendendo através daquele esquema os termos objetivos 
e subjetivos relevantes da relação" (SAHLINS, 2003, p. 9).

É nesse contexto que o conceito de significado se mostra pertinente para Sahlins, pois a cultura deve ser entendida como "ordens de significado de pessoas e coisas" (Idem). $O$ autor propõe que essas ordens de significado são sistemáticas - e não emanações caóticas do espírito humano - e que o papel do antropólogo seria desvendar esse sistema. É deste modo que pretende desautorizar a idéia de que os costumes seriam meras expressões fetichizadas das utilidades materiais da ordem social.

Os significados das ações humanas seriam formatados como projeções do esquema cultural que as sustentam num contexto específico; os efeitos da ação, portanto, seriam dados por uma relação de significação entre essa referência pontual - $a$ ação - e a ordem existente - a estrutura -, de modo que o evento pode ser entendido como catalisador de uma relação simbólica. E é no desdobramento do evento que, a partir da ação, a estrutura pode sr modificada.

O significado, nesse contexto, não

cria as forças materiais reais, mas, na medida em que estas são empregadas pelo homem, o significado cinge-as e governa sua influência cultural específica. Não se trata, então, de dizer que as forças não têm efeito real; simplesmente que elas não têm um efeito particular e também nenhuma existência cultural efetiva fora de sua integração em esquema simbólico e histórico dado. A mudança começa com a cultura, não a cultura com a mudança (Op. Cit., p. 31).

Sahlins reelabora questões do estruturalismo para estudar cultura e história: "sincrônico a princípio, ele [o estruturalismo] oferece a análise racional mais elevada para o estudo da diacronia" (Op. Cit., p. 29). É curioso que as idéias colocadas por Sahlins aqui pareçam mais palatáveis do que em seu trabalho posterior, notadamente "Historical Metaphors and Mythical Realities" (1981). Em "Cultura e Razão Prática", as colocações são feitas como apreciações do Estruturalismo, e não exatamente em termos apologéticos. Digo "exatamente" porque Sahlins ocupa um grande número de páginas fazendo uma reinterpretação estruturalista - de sucesso dentro do que propõe - de um trabalho anterior. Mas a questão da história, apesar de presente na avaliação teórica, não está presente na re-análise dos dados etnográficos. Se no trabalho de 1981 Sahlins pretende explicar um evento passado, a prova a que coloca a teoria é, no caso de "Cultura e Razão Prática", menos ardilosa.

De qualquer modo, quando perguntado sobre sua experiência na França com Lévi-Strauss, Sahlins faz as seguintes observações:

Impossible to summarize what I learned in 1968-9 in Lévi-Strauss's Laboratoire at the Collège. Allow me to epitomize: In 1969 I gave a seminar at the Labo on certain traditional systems of trade in Australia and Melanesia, prefaced by the disclaimer that I was no structuralist, as I was not talking about the exchange of women or words but of real-practical material infrastructure - the analysis of which, in any case, Lévi-Strauss had already conceded to Marx. In the discussion, Lévi-Strauss claimed that I was after all a structuralist, since what I had demonstrated in these material exchanges corresponded to certain structures of marital exchange he had described in The Elementary Forms of 
Kinship. I protested by citing the passage in La Pensée Sauvage where he says that structuralism is specifically a science of the superstructures. 'True', he replied, 'but you have to understand that I learned my anthropology at the feet of Franz Boas and Robert Lowie, who were speaking with reservation Indians about the customs of past generations' - 'the archaeology of the living', he called it. 'Nobody was paying attention to the current existence of the Indians. But now', he said, 'we have to extend structuralism to the infrastructures'. I replied that I thought his restriction of structuralism to the superstructures was a matter of scientific principle, so I had to ask, 'Just what is structuralism?' 'Énfin', he said, 'c'est la bonne anthropologie'. Of course, on those terms I agreed I was a structuralist (SAHLINS, 2008, p. 322).

Com relação ao marxismo, a preocupação de Sahlins era dialogar com o materialismo histórico enquanto articulador metodológico para a Antropologia. O contato com diversas culturas trouxe outras realidades sociais, em que a questão material era menos central - assim como o uso do marxismo parecia ser enquanto ferramenta teórica. Uma dessecação estrutural da vida social - a clássica dicotomia superestrutura e estrutura - parecia pouco útil ao trabalho antropológico: não só é difícil diferenciar nessas sociedades os aspectos materiais dos sociais - não que seja fácil na sociedade ocidental... -, como o interesse prático do homem na produção é uma construção simbólica, e esse interesse é completamente imbricado na lógica material. O próprio capitalismo pode ser entendido, portanto, através de um sistema simbólico construído.

Pode-se dizer que se a produção reflete o esquema geral da sociedade, ela não está senão se olhando no espelho.
Mas seria dizer a mesma coisa, e de uma forma que não descarta o entendimento já estabelecido do nosso próprio sistema e permite a comparação com os outros, observar que na cultura ocidental a economia é o lócus principal da produção simbólica. Para nós, a produção de mercadorias é ao mesmo tempo o modo privilegiado da produção simbólica e de sua transmissão. A singularidade da sociedade burguesa não está no fato de o sistema econômico escapar à determinação simbólica, mas em que o simbolismo econômico é estruturalmente determinante (SAHLINS, 2003, p.209).

Sahlins acaba, portanto, por motivar uma visão do marxismo como autoconsciência crítica da sociedade capitalista, fazendo da verdade do materialismo histórico ela própria histórica. $\mathrm{E}$ o modo como estabelece o diálogo entre a questão simbólica e a ordem material é relevante; dizer que a produção estrutura as relações sociais exatamente por ser o centro da produção simbólica na sociedade moderno-capitalista representou um passo importante para construção de uma visão não-unívoca da sociedade moderna.

Tem-se, assim, uma teoria cultural que está centrada em ordens de significado. Estaria em jogo, na análise cultural, a identificação de dinâmicas entre eventos e estrutura, gerando novas categorias para ordem simbólica. Por outro lado, é central em sua análise a maneira como identifica certos centros de produção simbólica, que nas sociedades moderno-contemporâneas seria a própria ordem capitalista.

\section{COMPARANDO TEIAS, ESTRUTURAS E CORRENTES}

Apesar das diferentes ênfases para conceito, cultura para Geertz, Sahlins e Barth é traduzível em significados. 
As diferenças de ênfase podem ser vistas no modo como operam analiticamente: Geertz pensa em teias de significados; Barth utiliza-se de correntes de tradições culturais que representariam universos discursivos significativos; Sahlins pensa em termos de estruturas, que apesar de não serem definidas de modo explícito, relacionam-se com signos e significados.

Geertz, assim, trabalha com significados de modo um tanto destacados do tecido social; sua análise efetivamente, para além da teoria que propõe, centra-se em formas culturais particulares - como é o caso da briga de galos - e sua conexão com o restante da vida cultural parece não ser levado em conta. Além disso, o trabaIho de Geertz entende os significados de modo unívoco, como se pessoas de uma mesma cultura partilhassem necessariamente os mesmo significados da mesma forma. Existe, assim, uma preocupação com uma forma cultural mínima, onde se percebe um todo cultural harmônico.

Barth tem interesse pelos processos mais longos e sua reverberação no cotidiano imediato; preocupa-se com a tradição e suas implicações na interação. Sem ser um interacionista clássico apesar de ter estudado em Chicago na década de 1950 e ter sido colega de Goffman -, a Antropologia de Barth desenvolve-se em torno das relações entre indivíduos. Se existe uma preocupação entre as tradições que são atribuidoras de significados, não é excluído o fato de que esses significados não são compartilhados por todos e que o lugar que ocupa um indivíduo em determinado evento é definidor do significado atribuído.

Sahlins, por sua vez, pretende a elaboração de uma estrutura que pudesse ser interpretada também diacronicamente. Os significados, assim, seriam ordenado- res de coisas ou pessoas em determinada cultura; e esse processo de ordenação seria feito através de um esquema simbólico apreensível. A estrutura, portanto, funcionaria como um contexto para significação; e se a estrutura se modifica através da ação ao longo do tempo, os significados atribuídos às ações também se modificam.

Sahlins e Barth, assim, possuem interesse na questão da história. Sahlins preocupa-se em identificar as mudanças da estrutura ao longo do tempo: a estrutura na história; já em Barth, a diacronia apresenta-se por conta da preocupação que o autor possui com a tradição cultural enquanto informadora do presente. Os significados são construídos ao longo do tempo.

Implícito nas três análises está o fato de a cultura ser tomada como apreensível; na verdade, essa talvez seja uma condição da Antropologia. Para além disso, Geertz propõe que a cultura seja pública e Sahlins parece fazer o mesmo. Barth, ao contrário, entende a cultura como sendo distributiva, e que o não-pertencimento seria, na verdade, revelador.

Viu-se, portanto, modos distintos de trabalhar com as noções de cultura. Se conceito permeia a análise dos três autores, seus lugares são em absoluto distintos e acabam por serem caracterizadores das teorias antropológicas propostas por Geertz, Barth e Sahlins, bem como de suas visões do universo social e dos problemas sociológicos com os quais pretendem dialogar.

\section{LINHAS PARA UMA DEFINIÇÃO DA GESTÃO CULTURAL}

Os modos como os Geertz, Barth e Sahlins exploram o conceito de cultura têm uma relação bastante próxima, como vimos, com as maneiras como compre- 
endem a prática antropológica. Nesse sentido, o horizonte de suas conceituações é a possibilidade de operar essas construções conceptuais para a realização etnográfica. A partir da retomada das características centrais dos conceitos de cultura desses autores, tentar compreender como essas questões podem ajudar a pensar a gestão cultural é um exercício interessante.

Sahlins preocupa-se, como vimos, desvencilhar de um utilitarismo que teria pouca utilidade para pensar as práticas culturais. Ou seja, os estudos sobre cultura não deveriam ocupar-se de entender questões simbólicas a partir de fórmulas utilitaristas, focada em ganhos materiais. O autor consegue estabelecer um diálogo efetivo entre a questão simbólica e a material; entre a maneira como a produção estrutura as relações sociais exatamente por ser o centro da produção simbólica no mundo moderno-contemporâneo.

A gestão cultural, como prática das sociedades contemporâneas ocidentais, reside - de maneira mais ou menos direta, dependendo da largura com que se compreende o conceito - exatamente nesse imbricamento entre material e simbólico. Não é o caso de explicá-la e instrumentalizá-la somente através de práticas habitualmente ligadas ao campo material; é necessário que se consiga articular tanto as dimensões simbólicas como as utilitárias, articular cultura e razão prática - já que elas não são verdadeiramente divisíveis.

Esse é um ponto fundamental para definição da prática e da formação do gestor cultural. De um lado, há uma série de relações que se ligam à áreas mais duras do conhecimento ou a práticas socialmente compreendidas como sendo de natureza puramente administrativa. Mas de outro há um universo sensível com o qual o gestor precisa lidar cotidianamen- te. A feitura dessa mediação, entre mundos aparentemente distantes, é uma característica fundadora da gestão cultural.

Se a cultura é um conceito dinâmico, como propõe Barth, cuja prática cotidiana é insumo para sua constante construção, as ciências que se utilizam da idéia precisam preconizar um trabalho de apreensão que se reconheça enquanto interpretação. Da polissemia da cultura nascem seus múltiplos usos. Cabe identificar, aqui, como o faz a gestão cultural. Geertz sugere que a melhor forma de entender o objeto de uma ciência ou disciplina é verificar o que os seus praticantes fazem.

Os gestores culturais preocupam-se com a concepção e distribuição de produtos artísticos, com as políticas públicas para a cultura, com as dotações de patrocínio de empresas, com os trabalhos sociais culturalmente orientados do terceiro setor; a questão, entretanto, é identificar para onde direciona essa prática, com que objetivo é feita, privilegiando quais atores sociais envolvidos no processo.

Pode-se entender a gestão cultural como aquela que facilita o consumo de bens culturais, ressaltando a capacidade de transformação advinda do exercício crítico incitado por essa prática entre os envolvidos nesse processo. A questão nesse caso, entretanto, é definir quais bens de consumo são culturais, ou melhor ainda, quais, contemporaneamente, não o são - haja vista a argumentação de Sahlins exposta no início do texto e também a objetificação de Baudrillard ou a colonização do imaginário de Jameson, para buscar amparos teóricos mais diversificados.

Argumentar, de outro lado, acerca da preconização do empoderamento dos beneficiários de uma gestão cultural pode 
parecer uma saída; mas se precisa definir quem são esses beneficiários - já que podem, virtualmente, variar dos espectadores de uma peça de teatro aos acionistas de uma sociedade anônima. Para além disso, dá poder como? Ou ainda, o que os empoderados farão com essa nova - e miraculosa - capacidade auto-gestão? Em que caminho será usado esse poder? Isso será estratégia da gestão cultural proposta?

Existem gestões de produtos artísticos, gestões públicas baseadas em plataformas políticas, gestões de ONGs (muitas vezes baseadas, também, em plataformas políticas...); gestões, enfim, que lidam de forma mais explícita - é imprescindível admitir - com mundos de símbolos criados para serem símbolos. Admitir-se um gestor cultural, nesse contexto, poderia ser uma espécie de filiação, seria assumir a possibilidade de produzir ideologia inerente a qualquer prática social - possibilidade essa que a maioria dessas práticas pretende esconder: "o caráter simbólico básico do processo [de trocas matérias, e portanto sociais] fica totalmente às escondidas dos participantes" (SAHLINS, 2004, p. 210) - mas com um objetivo específico.

Toda gestão que se diz cultural, portanto, pressupõe um posicionamento político, seja ele de que teor for. Por outro lado, sua definição é dada enquanto posicionamento que tem por definição a articulação de práticas diretamente ligadas e socialmente reconhecidas como simbólicas; deliberadamente criadas com tal fim.

A gestão cultural nessa perspectiva é a prática socialmente reconhecida que cria as condições de possibilidade - matérias e simbólicas - para que ações, instituições e projetos que engendram significados ganhem um espaço singular nas experiências humanas.
Se, como vimos, a cultura é formatada por teias de significados e seus estudos, a gestão cultural não se ocupa de todas as práticas culturais. Os significados socialmente compartilhados permeiam nossos cotidianos, são condicionais para vida humana em sociedade. Mas há momentos em que certos conjuntos de significados, sejam eles contidos numa obra de arte ou num ritual, ganham um status singular, socialmente estabelecido, que os destaca das práticas comezinhas cotidianas.

A gestão cultural, deste modo, se ocupa de criar os meios para que certas práticas culturais - num universo de significados certamente muito mais amplo ganhem um espaço singular para certa coletividade. A gestão cultural, portanto, se sustenta a partir de critérios socialmente reconhecidos para operar essa transposição, do comezinho para o que deve ser lembrado, visto e/ou disseminado. Nesse sentido, opera para a partir de um sistema de relações entre pessoas e instituições, que, articulados, formatam a produção, a distribuição, o uso e o consumo de algumas dessas práticas, objetos e ações culturais.

Esse processo de singularizar e dar status especiais a certas práticas culturais passam, na maioria das vezes, por alguma objetivação operada pela gestão cultural. É nesse sentido que uma festa cotidiana de certa comunidade pode ser tomada, num processo de objetivação que passa por práticas de gestão, como patrimônio imaterial; ou ainda, mais comumente, integrar certo projeto cultural, como um festival, por exemplo.

Essas objetivações operadas pela gestão cultural têm características centrais e recorrências importantes. Podem ser traduzidas em políticas culturais, projetos culturais, ações culturais, entre 
outras. Uma outra objetivação da gestão cultural está relacionada a espaços que são criados com o fim específico de abrigar a exposição, disseminação, uso e/ou consumo de certa prática cultural, os "espaços culturais".

Os espaços culturais, por exemplo, são assim classificados por serem alvo de uma agência específica, de esforços de pessoas e instituições articulados, para que certa atividade ou atividades culturais ocorram sistematicamente num determinado espaço. É importante ter em mente, contudo, que nos interessam aqueles espaços culturais que são criados e mantidos a partir da intervenção de mecanismos de gestão.

Uma Igreja, por exemplo, pode ser compreendida como um espaço de natureza cultural, já que é um lugar onde, a partir de esforços individuais e coletivos, uma atividade cultural específica ocorre sistematicamente. Mas uma Igreja só nos interessa como espaço cultural se for alvo de intervenções de práticas de gestão cultural. Assim, uma Igreja que está passando por um processo de tombamento e restauro ou que é alvo de um projeto cultural, como a realização de concertos de música sacra, ou que é visitada periodicamente por conta de sua relevância arquitetônica, se torna um espaço cultural passível de gestão cultural institucionalizada.

A agência objetivadora mais central da gestão cultural é, sem dúvidas, o projeto cultural. Ele é uma articulação discursiva que medeia a mudança de status de certo conjunto de significados para que possam ser reposicionados numa estrutura simbólica. A partir dele, têm-se a definição de ações a serem efetuadas, bem como o tempo, custos, recursos humanos, necessários para essa transformação.
Esse processo de reposicionamento coloca em contato inúmeros agentes, tanto gestores culturais como profissionais de outras naturezas. Essas diferentes objetivações que compõem a gestão cultural são traduzíveis numa divisão do trabalho específica. A interpolação mais óbvia é a dimensão do executor ou idealizador de um projeto e seus financiadores, sejam eles agentes públicos ou privados. Nesse sentido, um projeto cultural é o que estabelece parâmetros dessa relação em variados aspectos. E coloca em contato os gestores culturais responsáveis por esses pólos.

O gestor cultural, deste modo, é o operador de processos de objetivação que singularizam certo conjunto de significados a partir do contato com outros gestores. Cabe retomar, finalmente, uma característica central para cultura explorada por Barth, seu caráter distributivo.

A partir dessa proposição, temos que a cultura não é acessada do mesmo modo por todos os agentes que têm contato com um conjunto de significados. Barth dá o exemplo de um cortejo fúnebre que, se é acompanhado por diversas pessoas, tem apreensões distintas por cada uma delas: um familiar do morto tem um tipo de participação no processo; o oficiante, outro; um passante relaciona-se com a situação de maneira diferente.

Nos processos de gestão cultural, essa proposição tem duas implicações. A primeira delas diz respeito aos modos como cada um dos diversos agentes que são colocados em contato por práticas de gestão significam suas relações, tanto entre si como com o produto ou ação cultural propostos. O segundo ponto se relaciona à natureza mesma do conjunto de significados a partir dos quais os gestores culturais atuam inicialmente e transformam em alvos de seus projetos culturais. 
Singularizar certo conjunto de significados faz com que as relações estabelecidas com eles sejam também elas re-significadas. Assim, uma atuação da gestão cultural para fazer com que uma festa popular seja transformada em um festival faz com que as maneiras como essa era inicialmente vivida seja modificada. Talvez resida aí uma das questões políticas centrais das práticas de gestão cultural.

Como propõe Guattari há uma série de profissionais que têm atuação vocacionada para modificar os modos como os sujeitos se relacionam com o mundo; seriam aqueles mais propícios a "produção social de subjetividade". A prática de gestão cultural, desta maneira, poderia deve ser pensada como um posicionamento num universo simbólico que reordena, a partir de objetivações, algumas relações entre sujeitos e o mundo.

Nesse contexto, a ação de um gestor cultural é situada num universo de significados já existente - seria possível pensar a ação cultural, em alguns casos, na fórmula evento-estrutura-mudança proposta por Sahlins: um evento é compreendido a partir de categorias estruturais já conhecidas, mas por sua ação a estrutura pode ser, aos poucos modificada.

Essa questão é central para que o gestor cultural se assujeite de sua prática enquanto modificador, mesmo que de impacto reduzido, dependendo de suas ações, de estruturas sociais. O reposicionamento de certos significados tem implicações para os agentes que já o reconheciam como tal. Nesse sentido, a prática da gestão cultural deve ser refletida e, se pode funcionar como impulsionadora de certas atuações de modo positivo, pode também servir apenas para que certos agentes, institucionais ou não, tirem proveito de suas práticas sem levar em conta seus impactos para outros grupos.
A gestão cultural, portanto, parte, por um lado de um universo cultural amplo, marcado pelo compartilhamento de redes de significados; mas por outro, tem-se a singularização de alguns conjuntos desses significados através de objetivações específicas, que se perpassam a ordem material, não devem ser pensadas como tendo como fim último o utilitarismo ou o ganho econômico.

\section{Bibliografia:}

ANDERSON, Robert; BARTH, Fredrik. Interview with Fredrik Barth. Revista de Antropología Iberoamericana. Vol. 2, n. 2, 2007, pp. i-xvi.

BARTH, Frederik. A análise da cultura nas sociedades complexas. IN: LASK, Tomke (org.). O Guru, o iniciador e outras variações antropológicas. Rio de Janeiro: Contracapa, pp. 107-119, 2000.

BARTH, Fredrik. On the Study of Social Change. American Anthropologist, Vol. 69, n. 6, 1967, pp. 661-669.

BARTH, Fredrik. The Guru and the Conjurer: Transactions in Knowledge and the Shaping of Culture in Southeast Asia and Melanesia. Man, Vol. 25, n. 4, 1990, pp. 640-653.

BONET, Lluís. Gestion de projectos culturale. [s.n.b.]

FOUCAULT, Michel. Segurança, Território, População. São Paulo: Martins Fontes, 2008.

GEERTZ, Clifford. Descrição densa: por uma teoria interpretativa da cultura. IN: A Interpretação das Culturas. Rio de Janeiro: Jorge Zahar, 1978 A.

GEERTZ, Clifford. O senso comum como um sistema cultural. IN: O saber Local. Petrópolis: Vozes, 2000.

GEERTZ, Clifford. Um jogo absorvente: Notas sobre a Briga de Galos Balinesa. IN: A Interpretação das Culturas. Rio de Janeiro: Jorge Zahar, 1978 B. 
HANDLER, Richard; GEERTZ, Clifford. An Interview with Clifford Geertz. Current Anthropology, Vol. 32, n. 5, 1991, pp. 603-613.

JAMESON, Frederic. A Virada Cultural. São Paulo: Record, 2006.

PARSONS, Talcott. The Social System. London: Routledge \& Kegan Paul, 1979.

SAHLINS, Marshall. Cultura e Razão Prática. Rio de Janeiro: Jorge Zahar Editor, 2003.

SAHLINS, Marshall. Historical Metaphors and Mythical Realities: Structure in the Early History of the Sandwich Islands Kingdom. Ann Arbor: The University of Michigan Press, 1981.
SAHLINS, Marshall. Interview with Marshall Sahlins. Anthropological Theory. Vol. 8, n. 3, 2008, pp. 319-328.

SAHLINS, Marshall. On the Sociology of Primitive Exchange. IN: Stone Age Economics. Chicago: Aldine Publishing Company, 1972.

\footnotetext{
1 O termo em inglês, "streams of cultural tradition", é mais feliz para definir o que Barth pretende enfatizar com sua metáfora. A corrente de que o autor fala está mais ligada a correnteza dos rios do que às correntes com elos.
}

\section{Contato:}

Caio Gonçalves Dias caiogdias@gmail.com 